\title{
O Ideal Romântico do Sadomasoquismo
}

\section{Erotismo de autoayuda. Cincuenta sombras de Grey y el nuevo orden romántico.}

\section{ILLOUZ, EVa.}

Katz, Buenos Aires, 2014, 124p.

No livro Erotismo de autoayuda. Cincuenta sombras de Grey y el nuevo orden romántico, a socióloga Eva Illouz, da Universidade Hebraica de Jerusalém, escreve um ensaio no qual se propõe a discutir o que explica o sucesso de vendas entre o público feminino da trilogia Cinquenta Tons de Cinza, de E. L. James. O que instigou lllouz a fazer essa análise foi a constatação de que Cinquenta tons de cinza está longe de apresentar uma linguagem inovadora com relação à sexualidade' Nada que possa efetivamente distingui-lo dos romances eróticos destinados às mulheres que vêm sendo publicados nos últimos tempos.

Illouz ficou conhecida, especialmente, pelas suas reflexões sobre os fios que ligam capitalismo e sentimento nas esferas pública e privada. Seus livros Consuming the romantic utopia (1997) e Oprah Winfrey and the Glamour of Misery (2003) foram premiados pela Associação Americana de Sociologia. A autora se dedicou a demonstrar como, por influência do feminismo e da psicanálise foi criada uma nova matriz cultural que se desenvolveu ao longo do século XX, questionando o pressuposto básico do "capitalismo frio" de separação entre sentimento e razão (Eva ILLOUZ, 2008). No livro $O$ amor nos tempos do capitalismo (2011), são compiladas três conferências dadas por Illouz no Instituto de Pesquisas Sociais de Frankfurt, sob direção de Axel Honneth, nas quais ela faz uma síntese de suas pesquisas sobre as mudanças culturais do "capitalismo frio" para o "capitalismo afetivo".
Mais recentemente, seu olhar se volta para a discussão sobre a reorganização das relações de gênero em torno do amor. Em Why love hurts (2012), a autora vai construir uma explicação sociológica instigante para explicar as dores de amor na modernidade tardia. lllouz se propõe a debater as ambiguidades envolvidas nas liberdades emocional e sexual conquistadas pelas mulheres no século XX. Segundo ela, há uma dominação emocional masculina no mercado afetivo-sexual que não foi adequadamente discutida pelo feminismo. Ela aponta distinções entre a sexualidade masculina, mais voltada para o sexo casual e acumulativo, e a feminina, mais voltada para a exclusividade sexual e o envolvimento emocional, especialmente para aquelas mulheres que desejam o casamento e/ou a maternidade. Illouz acredita que o feminismo não se deu conta, em toda a sua extensão, de que a luta pela liberdade sexual para as mulheres pode ser, na verdade, a consagração de um modelo masculino de sexualidade. Ao colocar essa questão, Illouz almeja lançar luzes para o debate sobre a emancipação feminina e os obstáculos a serem superados para sua plena realização.

Ainda que Cinquenta tons de cinza tenha ficado mundialmente conhecido pelas práticas sadomasoquistas do casal de protagonistas, Christian Grey e Anastasia Steele, e seja possível identificar através de relatos de mulheres na internet e do crescimento de vendas nos sexshops dos produtos usados pelos protagonistas que o público, especialmente o feminino, foi tocado pelas narrativas da vida sexual do casal, essa não é a principal razão para justificar o sucesso de vendas da trilogia. Para Illouz, a novidade do livro está em contar, de forma não convencional, a história de amor entre um homem e uma mulher, apresentando o sadomasoquismo como utopia romântica.

Na trilogia é narrada a relação de Christian Grey, homem de negócios, superpoderoso, 
bonito, sexy e sádico, e Anastasia Steele, jovem estudante, virgem, que é construída e consolidada através das práticas sadomasoquistas. Steele é iniciada no sexo sadomasoquista por Grey, por quem se apaixona prontamente.

No primeiro volume da trilogia, Grey é apresentado como um "sensualista sem coração", parafraseando Max Weber, um homem que não deseja nada além do prazer sexual, estabelecendo sua relação com Steele baseada na assinatura de um contrato, no qual ela consente ser submissa a ele no sexo e manter sigilo sobre as práticas sexuais do casal. Inicialmente, Grey faz questão de salientar que o envolvimento entre eles está restrito ao sexo. Ao longo da trilogia, o "sensualista sem coração" torna-se um sensualista com coração, envolvendo-se emocionalmente. Não só se casa com Steele, como também desenvolve uma relação de simbiose com ela, demandando constantemente sua presença nas diversas esferas de sua vida. Steele, por sua vez, ainda que seja submissa no sexo, não o é nas outras esferas de sua vida. Ela trava uma constante luta com Grey em busca de sua autonomia e liberdade.

É possível perceber uma transformação nas identidades convencionais e fixas de gênero apresentadas no primeiro livro da trilogia para identidades mais fluidas e andróginas. Grey se conecta com os seus sentimentos e emoções, sem deixar de ser dominante no sexo, enquanto Steele conjuga submissão no sexo com uma crescente busca por autonomia e autorrealização fora da esfera erótica, colocando limites às demandas ilimitadas do poderoso Grey.

A tese defendida por Illouz é que o livro ganha o coração e a mente das mulheres, antes de tudo, por narrar uma história de amor em consonância com os ditames do código cultura feminista que se desenvolveu no século $X X$ Mesmo que Grey e Steele reproduzam no sexo as convencionais identidades de gênero, essas identidades são modernizadas fora da esfera erótica. Segundo Illouz, "fora da cama, o relacionamento é igualitário"2.

A trilogia não só trata dos conflitos das relações íntimas heterossexuais na modernidade tardia, como também fomenta fantasias românticas, oferecendo uma fórmula para resolução dos problemas e incertezas típicos dos relacionamentos amorosos nos dias de hoje. E é por isso que Illouz classifica o livro como "erotismo de autoajuda", reafirmando valores, com usos distintos pelo feminismo e pela cultura de autoajuda, como fortalecimento, autoempoderamento e automelhoramento do self.
Embora não classifique o livro como feminista, por não propor nenhuma alternativa à heteronormatividade tradicional, Illouz vê Cinquenta tons de cinza difundindo o ideal de autoafirmação feminina tão propagado pelo feminismo. Steele articula com clareza suas necessidades emocionais. É uma parceira sexual intensa e competente. Está o tempo todo renegociando as bases do contrato sexual com Grey. Além disso, nega-se a obter benefícios profissionais por ser casada com o dono da empresa em que trabalha e a adotar seu nome em função do casamento. Sem falar que faz questão de pagar a conta quando o convida para sair. Esses são alguns dos inúmeros exemplos dados no livro quanto ao empoderamento da protagonista.

Como é bastante comum nos encontros no mercado afetivo-sexual, em Cinquenta Tons de Cinza, "o sexo precede o romance". Grey e Steele se envolvem, a princípio sexualmente para, só mais tarde, a partir de muitas negociações, estabelecerem uma relação afetiva baseada no compromisso. Só que diferentemente do que ocorre nas "relações puras", para usar a expressão de Anthony Giddens (1993), as constantes negociações do casal não abalam o desejo nem desgastam a relação. Pelo contrário, o desejo é fomentado. Grey se "feminiliza" sem deixar de ser o hipermacho no sexo, ao mesmo tempo que Steele se "masculiniza" sem deixar de ser submissa nas práticas sadomasoquistas, ainda que force uma constante renegociação sobre elas.

Para Illouz, ainda que Cinquenta tons de cinza reproduza na esfera erótica os papéis tradicionais de gênero, o homem dominador e a mulher dominada, sua força está em fomentar em seus leitores e leitoras a fantasia em relação às certezas dadas pelas identidades fixas de gênero. O argumento desenvolvido pela autora é que o contexto de maior igualdade entre homens e mulheres, fruto das transformações nas relações de gênero, gerou uma indefinição sobre os papéis sociais masculino e feminino. Em tempos de androginia, homens e mulheres se indagam frequentemente sobre as regras de gênero. Sua percepção é de que homens e mulheres estão constantemente se interrogando sobre tais regras, se desejam ou não se ajustar a elas (ILLOUZ, 2015). Isso é uma fonte de ansiedade que não estava presente nas relações desiguais entre homens e mulheres sob a égide do patriarcado.

Isso não significa dizer que eles e elas sintam saudades das convencionais relações de gênero e aspirem atualizá-las em suas interações 
amorosas, mas que as relações de gênero binárias definiam, regulavam e organizavam as relações amorosas com maior clareza. Em outras palavras, - argumento de lllouz é que nas sociedades prémodernas as desigualdades de gênero estavam baseadas em relações de dependência entre homens e mulheres muito bem definidas pelas regras de gênero, que não só davam aos amantes previsibilidade e segurança em relação aos vínculos amorosos, como também Ihes proporcionavam prazer. A definição clara de papéis de gênero criava uma "dependência mútua natural" e um forte vínculo emocional, gerando "emoções mais espontâneas e imediatas" (ILLOUZ, 2014, p. 77), eliminando, assim, o desgaste envolvido nas negociações dos casais na contemporaneidade.

Em diálogo crítico com Cristina Nehring (2009) e outros autores que defendem que a igualdade com seus pressupostos de negociação, consentimento e reciprocidade não estimula o erotismo, lllouz não crê que a igualdade comprometa o desejo sexual. Para a autora, a questão é outra. A igualdade produz uma indefinição com relação às identidades de gênero, que passam a ser constantemente negociadas e renegociadas entre os casais, gerando uma série de sofrimentos psíquicos (ansiedades, incertezas, contradições, aborrecimentos etc.), que exprimem a dificuldade de os amantes conciliarem autonomia e apego nos dias de hoje. Ao identificar essa vantagem das relações desiguais entre os gêneros, Illouz não está fazendo uma avaliação política ou moral, mas sociológica, mostrando as ambivalências da igualdade ${ }^{3}$.

O sadomasoquismo em Cinquenta tons de Cinza oferece uma solução simbólica para as ambiguidades típicas das relações mais igualitárias entre homens e mulheres. Isso ocorre não só porque o sadomasoquismo define com clareza os papéis sociais a partir da dicotomia dominador/dominado, como também aparece como fórmula para superar as contradições e incertezas inerentes às relações amorosas entre iguais. Tudo se passa como se o sadomasoquismo pudesse garantir não só a manutenção do desejo, retirando-lhe seu caráter fluido e imprevisível, como também apagasse todo o desgaste envolvido nas negociações e renegociações do casal que na vida real, com frequência, colocam em xeque o próprio desejo.

Illouz constrói uma explicação sociológica bastante acurada sobre as ambiguidades das transformações das relações de gênero na esfera erótica. O sucesso de Cinquenta tons de Cinza é explicado, dentre outras coisas, pela sua capacidade de decifrar e apontar soluções para os dilemas das relações amorosas: a necessidade de conciliação de necessidades e desejos que, muitas vezes, são vistos como antagônicos - paixão e amor, liberdade e segurança, autonomia e apego 4 .

Para fazer sua análise sobre o sadomasoquismo em Cinquenta tons de cinza. Illouz recorre a estudos de outros especialistas sobre o tema. A autora enxerga o sadomasoquismo como mainstream, tendo sido visto desde a década de 1990 nos Estados Unidos como prática alternativa às práticas convencionais de sexo. 0 sadomasoquismo se legitima através de valores genuinamente modernos como autorrealização, liberdade e autonomia de escolha. Mesmo estando baseado na definição clara de papéis sexuais estilizados, o sadomasoquismo não os correlaciona às identidades fixas de gênero. Vários estudos apontam que homens superpoderosos apreciam ser dominados e submissos no sexo. Com isso, Illouz argumenta que as práticas sadomasoquistas ganham um caráter lúdico, permitindo que as mulheres fantasiem ser dominadas sem se sentirem humilhadas.

Além disso, o sadomasoquismo daria forma à dor. Os sofrimentos psíquicos comuns à instabilidade dos amores na modernidade tardia se transmutam em dor física, transformando sofrimento em prazer controlado pelos sujeitos. Há um empoderamento dos sujeitos na medida em que é feita essa releitura da dor e quem sofre a dor tem controle sobre ela. Aqui a autora parece comprar excessivamente o discurso dos praticantes de sadomasoquismo os quais advogam que a prática está baseada no consentimento dos sujeitos, sendo que eles podem, a qualquer tempo, interrompê-la. O sadomasoquismo é visto como um jogo erótico de poder realizado através de negociação entre os envolvidos, e não como um abuso físico ou emocional. Vários autores e autoras têm se preocupado em distinguir a tênue linha que separa prazer e perigo de reprodução de abusos e violências nas experiências sadomasoquistas. Aqui no Brasil Maria Filomena Gregori (2014) desenvolve pesquisas para examinar como prazeres e perigos dos erotismos têm sido tratados a partir da problemática do consentimento.

Mesmo não tendo explorado adequadamente esse aspecto, Illouz faz uma interpretação inovadora do sadomasoquismo, ao enxergá-lo como uma solução simbólica para lidar com as tensões e conflitos inerentes à sexualidade heterossexual. Reflexões sociológicas sobre as especificidades da sexualidade heterossexual vêm sendo relegadas a segundo plano nos 
estudos contemporâneos sobre sexualidade, que têm dado especial ênfase às investigações socioantropológicas sobre sexualidades "não

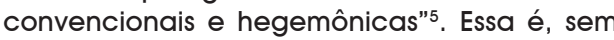
dúvida, uma importante contribuição de lllouz para os estudos de gênero.

\section{Notas}

1 Para maiores detalhes sobre as motivações que levaram Illouz a fazer essa análise, ver entrevista dada pela autora ao Jornal Frankfurter Allgemeine "Ein Gespräch mit Eva Illouz - Ist Sadomasochismus die Lösung?"

${ }^{2}$ Ver entrevista "A sexualidade é inevitável: hoje o sexo precede o amor" dada por Illouz ao Jornal El País.

${ }^{3} \mathrm{Em}$ entrevista dada ao jornal Frankfurter Allgemeine, Illouz faz questão de explicar essa diferença para a jornalista.

${ }^{4}$ Em seu livro Why love hurts (2012), Illouz faz uma discussão detalhada sobre os sofrimentos psíquicos produzidos pela dificuldade de conciliar essas demandas contraditórias nos relacionamentos amorosos. No capítulo 4 intitulado "The demand of recognition: love and the vulnerability of self", ela mostra as tensões entre autonomia $e$ reconhecimento nas relações amorosas, salientando que a autonomia se sobrepõe ao reconhecimento.

${ }^{5}$ Para uma discussão sobre o campo de estudos de sexualidade no Brasil, ver Júlio A. SIMÕES, e Sérgio CARRARA (2014).

\section{Referências}

GIDDENS, Anthony. A transformação da intimidade: sexualidade, amor e erotismo nas sociedades modernas. Trad. de Magda Lopes. São Paulo: Ed. UNESP, 1993.

GREGORI, Maria F. "Práticas eróticas e limites da sexualidade: contribuições de estudos recentes." Cadernos Pagu, n. 42, p. 47-74, jan-jun 2014.

ILLOUZ, Eva. "A sexualidade é inevitável: hoje o sexo precede o amor". A socióloga propõe uma surpreendente leitura de Cinquenta Tons de Cinza: entrevista. [30/03/2015] Madri, El País Disponível em <http://brasil.elpais.com/brasil/ 2015/03/26/cultura/1427384053 822164.html>. Acesso em 18/02/2016.

Erotismo de autoayuda. Cincuenta sombras de Grey y el nuevo orden romántico. Buenos Aires: Katz, 2014.

Ist Sadomasochismus die Lösung? Ein Gespräch mit Eva Illouz: entrevista. [22 de junho, 2013] Frankfurt, Frankfurter Allgemeine. Entrevista concedida a Johanna Adorján. Disponível em <http://www.faz.net/aktuell/feuilleton/bilderund-zeiten/interview/ein-gespraech-mit-evaillouz-ist-sadomasochismus-die-loesung12239460.html >. Acesso em 18/02/2016.

Why love hurts. Cambridge: Polity Press, 2012

. O amor nos tempos do capitalismo. Rio de Janeiro: Zahar, 2011

. Saving the Modern Soul: Therapy, Emotions, and the Culture of Self-Help. Los Angeles, Berkeley and London: University of California Press, 2008.

Oprah Winfrey and the Glamour of Misery. New York: Columbia University Press, 2003.

Consuming the Romantic Utopia. Love and the Cultural Contradictions of Capitalism. Los Angeles: University of California Press, 1997.

NEHRING, Cristina. A Vindication of Love: Reclaiming Romance for the Twenty-First Century. New York: Harper, 2009.

SIMÕES, Júlio Assis; CARRARA, Sérgio. "O campo de estudos socioantropológicos sobre diversidade sexual e de gênero no Brasil: um ensaio sobre sujeitos, temas e abordagens". Cadernos Pagu, n. 42, p. 75-98, jan-jun 2014.

Patrícia Castro Mattos Universidade Federal de São João del-Rei, São João del-Rei, Minas Gerais, Brasil 